\title{
AVALIAÇÃO DOS VALORES DE PROFESSORES: POSSIBILIDADES PARA UMA ESCOLA DEMOCRÁTICA
}

DENISE D'AUREA-TARDELI

\section{RESUMO}

Estudo derivado da pesquisa Avaliando valores em escolares e seus professores: uma proposta de construção de uma escala, desenvolvida pela Fundação Carlos Chagas. Pretende avaliar a identidade profissional de professores relacionada aos valores que estabelecem como prioritários. A metodologia envolve um questionário de valores e um questionário de perfil aplicados em aproximadamente 300 professores em exercício, do ensino fundamental (segundo ciclo) e ensino médio, em escolas públicas e privadas de São Paulo, para avaliar qual é o nível de presença e adesão aos valores de justiça, respeito, solidariedade e convivência democrática, para com isso envolver as variáveis identitárias dos professores e propor caminhos de intervenção. Os resultados apontam para professores com nível de adesão a valores correspondentes ao estágio pós-convencional da teoria kohlberguiana, possivelmente demonstrando que os valores são constructos centrais no exercício da sua profissão.

PALAVRAS-CHAVE VALORES MORAIS • PROFISSIONALIZAÇÃO

DOCENTE • KOHLBERG • IDENTIDADE PROFISSIONAL. 


\section{RESUMEN}

Un estudio derivado de la investigación Avaliando valores em escolares e seus professores: uma proposta de construção de uma escala (Evaluando valores en escolares y sus profesores: una propuesta de construcción de una escala). Pretende evaluar la identidad profesional de profesores relacionada con los valores que establecen como prioritarios. La metodología abarca un cuestionario de valores y un cuestionario de perfil aplicados a cerca de 300 profesores en ejercicio, de la educación básica (segundo ciclo) y media, en escuelas públicas y privadas de São Paulo, para evaluar cuál es el nivel de presencia y adhesión a los valores de justicia, respeto, solidaridad y convivencia democrática, para con ello involucrar las variables de identidad de los profesores y proponer caminos de intervención. Los resultados ponen de manifiesto docentes con nivel de adhesión a valores correspondientes a la etapa post-convencional de la teoría kohlberguiana, lo que demuestra posiblemente que los valores son constructos centrales en el ejercicio de su profesión.

PALABRAS CLAVE VALORES MORALES - PROFESIONALIZACIÓN DOCENTE • KOHLBERG • IDENTIDAD PROFESSIONAL.

\section{ABSTRACT}

Study derived from the research Avaliando valores em escolares e seus professores: uma proposta de construção de uma escala. It intends to evaluate teachers' professional identity insofar as the values they set as prioritary are concerned. The methodology comprises both a values form and a profile form filled in by approximately 300 working teachers of junior high schools and high schools, in public and private schools of Sao Paulo, in order to evaluate the level of presence and commitment to values of justice, respect, solidarity and democratic coexistence, thus involving teachers' identity variables and proposing possible interventions. The results show teachers to be committed to values at a level equivalent to the post-conventional stage of the Kohlbergian theory, possibly demonstrating that values are central constructs in their professional practice.

KEYWORDS MORAL VALUES • FACULTY PROFESSIONALIZATION • KOHLBERG・PROFESSIONAL IDENTITY. 


\section{INTRODUÇÃO}

A pesquisa em questão é derivada do projeto Avaliando valores em escolares e seus professores: uma proposta de construção de uma escala, desenvolvida pela Fundação Carlos Chagas, que tem como objetivo mensurar a presença e a adesão de valores - justiça, solidariedade, convivência democrática e respeito mútuo - nos julgamentos que escolares e seus professores fazem em histórias hipotéticas da vida cotidiana, em vários contextos, escritas na forma de situações-problema, por meio da construção de um instrumento que pretende não só mensurar se os respondentes se colocam a favor ou contra cada um desses valores, mas o quanto aderem a eles, dentre alternativas que expressam diferentes níveis de julgamento sociomoral.

Esta pesquisa pretende compreender a formação da identidade profissional de professores egressos de licenciaturas variadas, procurando identificar a construção das dimensões morais, discutir teoricamente limites, dificuldades e possibilidades de procedimentos de atividades com valores, pensar nas condutas da boa convivência escolar, baseando-se no instrumento mencionado acima. 
De acordo com Piaget (1994), um valor é um investimento afetivo que nos faz agir, que nos move para uma direção. E os valores morais são, portanto, os investimentos afetivos que colocamos em regras, princípios, ideias e sentimentos, e que influem em julgamento e ações consideradas, na maioria das culturas, como boas ou justas. É o que nos guia para os chamados bons costumes. Com essas considerações é possível compreender o interesse no tema e em como implementar programas efetivos que promovam valores individuais $\mathrm{e}$ sociais nas escolas. Parte desse material se explica pela necessidade que as sociedades têm identificado de enfatizar valores éticos que permitam a convivência pacífica de seus cidadãos e a implementação de seus sistemas democráticos.

De acordo com Vazquez (1993), valores são atribuições realizadas por sujeitos sociais sobre propriedades de objetos, dos acontecimentos e de ações, sejam estes naturais ou produtos humanos. Nesse sentido, valores não são realidades concretas residentes nos próprios objetos ou na natureza, como se propõe em visões muito objetivas, nem são resultados de avaliações pessoais de um sujeito individual, como se pensa em visões subjetivistas. Ao valorizar algo, o sujeito o faz a partir de elementos de sua cultura, de saberes coletivos em que está imerso e que podem se relacionar, mais fortemente ou menos intensamente, com o seu grupo de pertença. Por isso, toda a ação de avaliar ou de valorizar algo reproduz, modifica e/ou reconstrói valores que foram anteriormente construídos. Por outro lado, quem valoriza algo o faz também com base em certas propriedades que estão nos objetos e não apenas nos critérios dos próprios sujeitos. Um mesmo objeto pode ser valorizado em função de diferentes aspectos: estéticos, funcionais ou utilitários e morais, pois a valorização depende de quem a faz e para quê. Tal como nos explica Vazquez (1993, p. 121): “O valor não é propriedade dos objetos em si, mas propriedade adquirida graças à sua relação com o homem como ser social. Mas, por sua vez, os objetos podem ter valor somente quando dotados realmente de certas propriedades objetivas". Ou, ainda,

É o homem - como ser histórico e social - e com a sua atividade prática, que cria os valores e os bens nos quais 


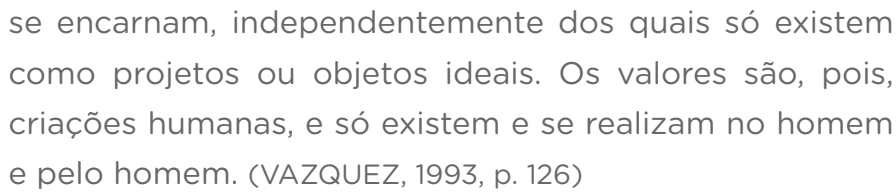

Soma-se ao tema dos valores a discussão sobre a identidade profissional do docente, que constitui o "mecanismo mediante o qual os professores se reconhecem a si mesmos e são reconhecidos por outros como membros de uma determinada categoria social, a categoria dos professores" (GYSLING, 1992, p. 12). Essa identidade não surge automaticamente como resultado da obtenção do título de professor, mas, ao contrário, é preciso construí-la. Essa construção requer um processo individual e coletivo, é de natureza complexa e dinâmica, e se mantém durante toda a vida profissional, o que permite ao sujeito a configuração de representações subjetivas e coletivas acerca da profissão docente.

A construção de uma identidade profissional é um processo contínuo sobre um todo social, familiar e, especialmente a partir da longa história escolar que marca a socialização básica, como mostram as histórias de vida profissionais. Como disse Tardif (2004), os saberes experimentais do docente profissional derivam, em grande parte, de preconcepções de ensino e aprendizagem herdadas da história da escola, porque já estão aprendendo o ofício antes de iniciá-lo.

A identidade profissional costuma ser um resultado de um longo processo de construção da maneira particular de se sentir professor, de atribuir sentido à experiência cotidiana. Segundo Bolívar (2006), é o resultado de um processo que integra diferentes experiências do indivíduo durante sua vida, marcada por rupturas e permanências. Além disso, é construída por meio de um conjunto de dinâmicas e estratégias identitárias que vão se constituindo em torno do exercício da profissão. As experiências escolares vivenciadas com os alunos desempenham um papel-chave nesse processo, o quanto é atrativa a docência, sua primeira formação, o início de sua prática profissional; tudo isso compreenderá de forma positiva ou negativa o futuro professor. 
A identidade profissional se forma, então, por meio de um processo de socialização profissional no exercício da prática, com a aquisição de normas, regras e valores da profissão. A identidade apresenta duas dimensões segundo Barbier (1998) e Dubar (1997), que estão relacionadas dialeticamente entre si, que articulam o individual e o estrutural num duplo processo: as construções que o sujeito faz de si mesmo - identidade para si, projeto identitário - e representações que os outros fazem dele - identidade para o outro, reconhecimento identitário. A primeira se configura com base em um processo de apropriação subjetiva da identidade social, das categorias de pertencimento e das relações afetivas; a segunda é uma atribuição e um reconhecimento da identidade docente, baseados nas instituições e nas pessoas com as quais o professor interage.

A identidade profissional docente é, portanto, o resultado de um processo biográfico e social, dependente da formação inicial e da socialização profissional nas condições de exercício da prática profissional. É uma construção singular, ligada à história pessoal e aos múltiplos vínculos que carrega consigo - sociais, familiares, escolares e profissionais.

\section{METODOLOGIA}

Este estudo tem como objetivo geral avaliar a presença e a adesão de valores democráticos em professores em exercício docente egressos dos cursos de pedagogia e outras licenciaturas, envolvendo variáveis identitárias a serem discutidas e comparadas com base em categorias estabelecidas por instrumento específico de avaliação de valores. Tal proposta se insere numa perspectiva psicossocial de avaliação dos processos de formação do professor, tendo em vista a elaboração de indicadores preditivos de seu desempenho escolar, voltados para as práticas de convivência democrática.

A identidade profissional do professor tem sido confrontada, como salienta Day (2005a), como um conjunto de atribuições "que se centram na melhoria das escolas e do desempenho dos alunos no quadro de um conjunto restrito e mensurável de disciplinas, capacidades ou competências" (s/p), fazendo com 
que sua identidade anterior - período da formação - entre em conflito com sua identidade profissional que é, em grande parte, determinada pelas atribuições que os outros definem para ela, e pelas próprias experiências, abalando os valores ético-morais anteriormente prevalecentes.

Assim, a pergunta que se estabelece é: qual é o nível de presença e a força da adesão de determinados valores no professor em exercício, para a compreensão de sua identidade profissional, no que se refere às práticas de convivência democrática?

Como hipótese, podemos pensar que o nível de adesão aos valores, sendo alto ou baixo, pode refletir algumas características construídas na formação do professor, características estas que são necessárias para um trabalho bem-sucedido na resolução de conflitos, no respeito às diferenças, no estabelecimento da boa convivência e na compreensão coerente das normas escolares. Professores com valores desejáveis universalmente constituídos podem ser mais inclinados a desenvolver uma prática escolar mais democrática e, consequentemente, proporcionar aos alunos um ambiente mais inclusivo e solidário. Já os professores que demonstram valores mais hedonistas ou materiais, que se preocupam primeiramente com suas necessidades e satisfações, podem estar mais voltados para uma prática escolar mais individualista, menos cooperativa e mais autoritária.

Para tal, os objetivos específicos da pesquisa são os seguintes:

- avaliação da presença e adesão de valores em professores, no julgamento que fazem de situações hipotéticas da vida cotidiana;

- compreender a identidade profissional de professores egressos dos cursos de pedagogia e licenciaturas, da rede pública e privada, procurando identificar a construção das dimensões morais de sua formação, com base nos elementos que permitem articular as habilidades e os conhecimentos construídos;

- investigar os valores referentes a justiça, solidariedade, respeito e convivência democrática, e suas possibilidades de aplicação nas atividades cotidianas escolares; 
- identificar e comparar categorias de desenvolvimento moral dos professores, baseadas nas respostas coletadas em instrumento de avaliação de valores específico.

Como procedimentos metodológicos, foram selecionados cerca de 300 sujeitos egressos de cursos de pedagogia e licenciaturas, em exercício da docência, de instituições escolares públicas e privadas. Os professores foram selecionados para a pesquisa por meio dos contatos dos pesquisadores do projeto-mãe, assim como dos contatos da própria Fundação Carlos Chagas. Os procedimentos éticos de pesquisar foram adotados para essa coleta.

Em relação aos instrumentos de coleta, foram utilizados os mesmos materiais que foram desenvolvidos pelo projeto-mãe:

- questionário de perfil para identificação do nível socioeconômico e cultural;

- questionário de valores para professores - material inédito, elaborado especialmente pela pesquisa. Entre os itens elaborados para este instrumento, 41 foram utilizados para os questionários dos professores, distribuídos em dois cadernos.

Sabemos que existem, há décadas, formas de avaliação do julgamento moral e que são consagradas como instrumentos competentes, como os testes baseados nos dilemas morais e originados nas entrevistas de Kolhberg (1992) e seus seguidores (KOLLER et al., 1994; LIND, 2000; REST, 1986), no entanto, o instrumento utilizado na pesquisa desenvolvida pela Fundação Carlos Chagas é original, voltado às questões da atualidade, ao contexto brasileiro. Os itens foram construídos na forma de situações-problema, inspirados em cenas do cotidiano de crianças, adolescentes e professores, que ocorrem em diferentes lócus, como família, ambientes públicos diversos, escola e internet.

Nas alternativas, foram enfatizados os três níveis kohlberguianos, principalmente a perspectiva social em que o indivíduo se coloca em relação a si mesmo, às expectativas dos outros, às normas, à sociedade, ou frente 
aos princípios universais mais amplos. Assim, destacamos nos níveis, respectivamente, uma perspectiva individualista ou "egocentrada" (nível 1), outra centrada nas relações grupais, familiares e em normas sociais mais convencionais (nível 2), e, finalmente, outra perspectiva, mais descentrada socialmente, baseada em contratos estabelecidos democraticamente por meio de procedimentos justos e em princípios considerados "universalizáveis" (nível 3).

Em função dessas perspectivas sociais correspondentes aos níveis, foram colocadas cinco alternativas: três em que o valor focado é afirmado - "pró-valor" - sendo uma em cada um dos níveis de perspectiva social: nível 1 , a alternativa foi denominada $=\mathrm{P}$ 1; nível 2, a alternativa foi denominada $=\mathrm{P} 2$; e nível 3, a alternativa foi denominada $=$ P3. E duas alternativas que afirmam o "contravalor" correspondente, sendo uma delas no nível 1 , denominada $=\mathrm{C} 1$ e outra no nível 2 , denominada $=\mathrm{C} 2$.

Chamamos a atenção para o fato de que neste instrumento não foram apresentadas alternativas com contravalor em nível 3 (equivalente ao pós-convencional), pois entendeu-se que elas seriam moralmente impossíveis, já que para serem pós-convencionais, envolveriam novos valores que não os contemplados na história.

\section{RESULTADOS}

A amostra proposta consistiu de 314 professores de perfis variados. Resumidamente, podemos identificar esses sujeitos como $88,9 \%$ do sexo feminino, sendo somente $11,1 \%$ do masculino; as faixas etárias predominantes são de 30 a 39 anos, com $32,5 \%$, e de 40 a 49 anos, com 31,2\%. A maioria é casada, $61,2 \%$ da amostra, e $62,3 \%$ têm filhos. A Tabela 1 é destacada porque interessa especificamente à pesquisa: 
TABELA 1 - Percentual de professores quanto à formação e experiência profissional

\begin{tabular}{|c|c|c|}
\hline & & $\%$ \\
\hline \multirow{2}{*}{ Escolaridade } & Nível Superior & $55,1 \%$ \\
\hline & Especialização & $38,3 \%$ \\
\hline \multirow{2}{*}{$\begin{array}{l}\text { Onde cursou a graduação e a } \\
\text { educação básica }\end{array}$} & Curso superior em instituição privada & $79,7 \%$ \\
\hline & Cursou a educação básica somente em escola pública & $60,6 \%$ \\
\hline \multirow{3}{*}{ Formação continuada } & Após a graduação (para áreas variadas) & $100,0 \%$ \\
\hline & Metodologias de ensino & $30,1 \%$ \\
\hline & Temas sobre valores morais & $9,4 \%$ \\
\hline \multirow{3}{*}{ Experiência profissional } & Até 5 anos & $23,1 \%$ \\
\hline & De 6 a 10 anos & $21,0 \%$ \\
\hline & De 11 a 15 anos & $19,0 \%$ \\
\hline
\end{tabular}

Fonte: Elaboração da autora.

Outro dado é que $95,1 \%$ dos pesquisados afirmaram que se sentem muito bem nas escolas em que atuam e que são valorizados. São sujeitos que parecem priorizar a família, as amizades, o bem-estar, o respeito e as regras sociais.

\section{DISCUSSÃO}

Podemos tecer algumas conclusões e levantar algumas hipóteses para análise:

a) Os resultados da aplicação da escala de valores apontam para professores moralmente amadurecidos e com nível de adesão a valores correspondentes ao estágio pós-convencional, segundo Kohlberg (1992). Naquilo que podemos comparar, essa constatação cumpre os objetivos básicos da pesquisa sobre a verificação da adesão a valores e como isso corresponde aos níveis de amadurecimento moral.

De acordo com Kohlberg (1992), além de os níveis de raciocínio moral dependerem de um desenvolvimento cognitivo (relação necessária, mas não suficiente), dependem também de uma evolução na perspectiva social ou percepção social, ou ainda da habilidade de assunção de papéis. Esse campo 
descreve a "percepção do fato social” (KOHLBERG, 1992, p. 195), ou "como as pessoas veem as outras, interpretam seus pensamentos e sentimentos e consideram o papel e o lugar que ocupam em sociedade” (KOHLBERG, 1992, p. 186). Selman (1980) define essa percepção social como a forma como o indivíduo diferencia e relaciona a sua perspectiva da de outros (SELMAN, 1980; KOHLBERG, 1992). Há estágios de desenvolvimento da perspectiva social que seriam mais gerais que os de desenvolvimento moral, pois não tratam especificamente de situações de justiça, nem de escolher entre o que é correto ou incorreto. Para Kohlberg (1984), fazer um juízo num certo nível é mais difícil do que simplesmente ver o mundo em um desses níveis de perspectiva social. Tal como ocorre com a lógica, "o desenvolvimento da percepção social de um estágio ocorre antes ou é mais fácil que o desenvolvimento do estágio paralelo de juízo moral" (KOHLBERG, 1984, p. 186).

O instrumento aplicado e os resultados coletados não dão conta de avaliar o raciocínio moral, o nível de juízo moral, mas, sim, a percepção da perspectiva social e como os sujeitos estão inclinados a aderirem aos valores sociais. Como já explicamos anteriormente, a alternativa P3 corresponde ao nível de desenvolvimento moral mais evoluído segundo Kohlberg (1984) e a escolha dessa alternativa projeta a percepção da perspectiva social pela adesão aos valores que corresponderia a esse nível de desenvolvimento moral. A ideia é avaliar a projeção do sujeito frente às suas escolhas.

A moralidade pós-convencional, segundo Kohlberg (1984), é o nível em que os valores morais são aceitos conscientemente. Esse nível inclui dois estágios (5 e 6) que explicam a perspectiva que recorre à natureza da moralidade ou ao fato de que as pessoas são fins em si mesmas e devem ser tratadas como tal. O estágio 5 se refere ao certo e ao errado, como dependentes de padrões aprovados pela sociedade como um todo. A pessoa sente que tem obrigação de obedecer à lei, mas entende que as leis não são absolutas, ou seja, podem ser mudadas se todos concordarem. Nos casos em que a lei não se pronuncia, o que é certo ou errado é decidido pela opinião pessoal ou por um acordo entre pessoas. Nesse estágio, impera a moralidade do contrato social e da 
lei, democraticamente aceitos. O estágio 5 , em suma, fala da preocupação com o respeito da comunidade e de si próprio.

Já o estágio 6 se refere ao certo e ao errado, decididos pela consciência de cada um, baseada em princípios éticos, abstratos, gerais e universais. Os princípios éticos referem-se a justiça, igualdade e dignidade de todos os seres humanos. Esses valores e princípios morais têm validade e aplicação independentes da autoridade.

Kohlberg (1984) afirma que o desenvolvimento do julgamento moral evolui de estágios em que predominam o medo da punição e o valor da recompensa, para o de conformismo ao grupo, até chegar ao da autonomia e de princípios de consciência individuais. Por isso, se os professores estão amadurecidos moralmente, se os resultados desta pesquisa podem sugerir isso, eles podem estar mais aptos a realizar debates sobre questões morais com seus alunos, a encorajá-los em afirmações e julgamentos morais, o que é muito bom. Se os professores puderem promover experiências significativas nas idades apropriadas dos seus alunos, facilitarão o amadurecimento deles e poderão evitar a estagnação dos julgamentos morais em estágios menos amadurecidos. Portanto, os professores em exercício precisam de atualização constante de conhecimentos, de competências e de destrezas para desenvolverem valores, amadurecerem moralmente e formarem as suas identidades.

Somente a prática da reflexão crítica pode favorecer o questionamento das situações escolares, enfrentando e analisando suas contradições, dissonâncias e dicotomias. É precisamente essa prática que permite reconhecer os matizes morais e políticos do discurso educativo e os componentes éticos da ação prática, o que facilita a construção de concepções e permite estabelecer um diálogo com os aspectos subjacentes das perspectivas curriculares. Ou seja, permite a visualização de todos os aspectos tradicionalmente ignorados e descarta a crença bastante generalizada de que tudo que acontece na escola é inócuo ou objetivo.

Uma formação de professores que promove a prática da reflexão crítica baseia o processo formativo na análise dos problemas escolares. É uma formação que atribui valores aos 
conteúdos como produtos históricos que precisam ser questionados e subscreve a ideia de que a escola não é um terreno neutro, ao contrário, é uma realidade mediada por fatores sociais e subculturais, por conflitos e contradições (ALVARADO; OSPINA, 1998). Dessa forma, considera que a aprendizagem representa uma construção pessoal, que não se trata de um processo solitário, mas, ao contrário, está marcada num contexto social que opera por meio de interações que requerem a compreensão de significados e de valores da contemporaneidade.

A reflexão crítica num trabalho com valores representa uma atividade central na formação profissional, não somente porque gera novas compreensões, novas maneiras de ver, ser e atuar, mas também porque desenvolve uma disposição para promover sua prática, dado que

A profissionalização docente leva a sério nos debates e crescentes consensos [...] que definem os profissionais a partir de um alto domínio de saberes e competências cognitivas que se obtêm somente na formação inicial de nível universitário e que devem imperativamente atualizar-se em uma efetiva formação contínua. (NUÑEZ, 2000, p. 5)

Os professores, para formar eticamente seus alunos, precisam, antes de mais nada, ter desenvolvido algumas competências, e a autonomia moral é uma delas. Ela é a capacidade de escolher o princípio adequado para cada caso e procurar dar uma interpretação mais justa para as situações conflitivas. Essa capacidade é a que nos faz responsáveis pelas ações ou pelas omissões, pois todo indivíduo tem de responder, diante de si próprio e frente aos outros, àquilo que fez ou não fez, ou que poderia ter feito.

b) A partir dos índices estatísticos da aplicação da escala que indicam forte adesão aos valores moralmente desejados, podemos supor, como outro aspecto para análise, que isso pode ter relação com o fato de esses professores vivenciarem experiências cotidianas em suas escolas de trabalho que os levam ao desenvolvimento moral e ao exercício da cidadania mais adequadamente. Podemos pensar que são profissionais que trabalham em escolas que valorizam as 
comunidades de aprendizagem, pois, apesar de não termos esses dados apurados concretamente, segundo o questionário de perfil, $95,1 \%$ da amostra se sentem muito bem nas escolas em que trabalham e $65,4 \%$ têm a sensação de serem bem-vistos pelos seus pares nesses ambientes, dados que podem ser relevantes.

É necessário considerar um trabalho de cooperação entre escolas em torno de projetos coletivos centrados na cidadania e na ética. Nesse sentido, Fullan (2001) nos remete para a ideia de lideranças que visem ao sucesso de todos os alunos, de uma visão partilhada pela comunidade educativa acerca da aprendizagem, de uma cultura de escola e de programas institucionais apropriados a essa aprendizagem e ao desenvolvimento dos agentes educativos; e, ainda, de uma gestão da organização e dos recursos, de uma colaboração dentro e fora da escola, das famílias e dos membros das comunidades com outras escolas, de uma colaboração e de uma conduta ética e justa.

Escolas que fazem esse tipo de trabalho, que discutem questões sobre desigualdade, inclusão, injustiças, desrespeito etc. como temas que foram abordados no questionário de valores aplicado, estariam mais inclinadas a desenvolver o senso ético de seus professores, pois essas práticas reflexivas, como falamos no item anterior, são elementos fundamentais para a tomada de consciência e construção de valores democráticos. Isso implica um novo profissionalismo "colaborativo, não autônomo, aberto mais do que fechado, orientado para fora mais do que insular, autoritário mas não controlador" (FULLAN, 2001, p. 265). A participação colaborativa, "encarada numa perspectiva ética como um direito, um dever e uma responsabilidade, poderá constituir, à medida que se for ampliando e aprofundando, uma forma de real democratização da educação" (CAETANO, 2003, p. 29).

Nessas comunidades de aprendizagem e em escolas democráticas, espera-se que a colaboração facilite a quebra de compartimentalizações, que aumente a capacidade de reflexão e a redução das incertezas, que haja o aumento da assertividade política dos professores em relação a inova- 
ções e reformas, além da predisposição para uma participação em decisões organizacionais, para o desempenho de funções de liderança e para um desenvolvimento continuado (HARGREAVES, 1998).

c) Os trabalhos cooperativos nas escolas remetem a outra ideia, que é a da formação continuada de professores e o desenvolvimento profissional. Também como hipótese, podemos argumentar que a forte adesão a valores eticamente desejáveis nas respostas do questionário pode ter relação com a continuidade da formação e com o aprimoramento profissional constantes, já que $100 \%$ da amostra pesquisada fizeram vários cursos após a graduação, em várias temáticas educacionais, segundo o questionário de perfil. Notificamos que $9,4 \%$ fizeram cursos específicos sobre valores morais e 38,3\% fizeram cursos de especialização/lato sensu.

Termos como aperfeiçoamento, formação em serviço, formação contínua, reciclagem, desenvolvimento profissional ou desenvolvimento de professores foram usados como conceitos equivalentes. Marcelo (1999) propõe o uso do conceito de "desenvolvimento profissional de professores", uma vez que se adapta ao professor como profissional de ensino. O conceito de desenvolvimento pressupõe evolução e continuidade, o que parece superar a simples justaposição entre formação inicial e aperfeiçoamento dos professores. Além disso, esse conceito pressupõe uma abordagem que valoriza o seu caráter contextual, organizacional e orientado para a mudança na formação de professores.

Para Day (2007, p. 20-21),

O desenvolvimento profissional envolve todas as expe-

riências espontâneas de aprendizagem e as atividades conscientemente planificadas, realizadas para benefício, direto ou indireto, do indivíduo, do grupo ou da escola e que contribuem, através destes, para a qualidade da educação na sala de aula. É o processo através do qual os professores, enquanto agentes de mudança, reveem, renovam e ampliam, individual ou coletivamente, o seu 
compromisso com os propósitos morais de ensino, adquirem e desenvolvem, de forma crítica, juntamente com as crianças, jovens e colegas, o conhecimento, as destrezas e a inteligência emocional, essenciais para uma reflexão, planificação e prática profissionais eficazes, em cada uma das fases das suas vidas profissionais.

Como diz Estrela (2002, p. 116), “é na escola e pela ação no cotidiano que se revelam as necessidades de formação do professor, se forja a sua identidade profissional e se afirma o seu projeto de vida”, e podemos acrescentar que tudo isso se resume à interação com os seus pares, que pode ser potencializada pela participação em projetos integrados de trabalho.

No que diz respeito à formação de professores, busca-se cada vez mais pela formação continuada - ou como diz Day (2007), pelo desenvolvimento profissional contínuo - para que ocorra o desenvolvimento de competências profissionais que só podem acontecer em contato com seus pares no local de trabalho.

Várias pesquisas se associam à eficiência do desenvolvimento profissional contínuo em escolas que mantêm culturas de aprendizagem para professores (FULLAN, 2001; GATTI, 2003). Tais escolas combinam trabalho escolar colaborativo com trabalho individual e autônomo, incluindo aprendizagem intrapessoal por meio de formas de reflexão (DAY, 2005b), e combinam o desenvolvimento profissional contínuo com as necessidades profissionais e pessoais, de prazo mais longo, com projetos de sala de aula, de prazos mais curtos.

A formação continuada de professores traz um conjunto de questões relacionadas não só com a formação propriamente dita, mas igualmente com aspectos em que esta se integra com o desenvolvimento das escolas enquanto locais, ao mesmo tempo, de trabalho e de aprendizagem de alunos e professores.

d) Outra possibilidade de análise pode estar relacionada ao fato de que os professores são mais ou menos eficientes, em relação às suas próprias percepções e ao progresso e à condução dos alunos em cada fase de 
sua vida profissional, segundo Day (2007), pelo tempo de vida profissional e a própria idade cronológica em que estão em exercício. Em cada fase, os professores podem detectar uma eficiência crescente, embora a cada uma correspondam diferentes desafios e preocupações. Parte dos professores pesquisados $(23,1 \%)$, segundo o questionário de perfil, concentram o exercício de sua vida profissional no período entre 0 e 5 anos, e parte (21\%), entre 6 e 10 anos de atuação profissional.

Para Day (2007), entre 0 e 3 anos, o envolvimento com a profissão preconiza o apoio e o desafio. $O$ enfoque é um sentimento crescente de eficácia na sala de aula, além do apoio aos gestores. Nessa fase em que estão praticamente iniciando a carreira, os professores veem o mau comportamento dos alunos como um impacto negativo e procuram resolver esses problemas com empenho. $\mathrm{O}$ autor também constatou em suas pesquisas que, entre 5 e 7 anos de exercício profissional, a eficácia na sala de aula é a característica-chave para o aumento da confiança na capacidade de ser um professor eficiente; são professores capazes de manter um forte sentimento de identidade, autoeficácia e competência naquilo que fazem.

Aparecem ainda, na pesquisa, $19 \%$ de professores entre 11 e 15 anos de exercício profissional. Esse período, apesar de apresentar um intervalo de tempo de quase 10 anos da primeira categoria, é igualmente interessante para a análise, porque, conforme os estudos de Day (2007), esse é o momento de tensões e transições constantes. Essa fase é vista como um marco no desenvolvimento profissional, que motiva os docentes a tomarem decisões sobre a progressão de suas carreiras. Ou seja, tanto nos professores que estão há pouco no exercício profissional, como nos que já atuam há mais de 10 anos, as características de perfil apontam para profissionais motivados com a carreira, com ânimo para desenvolver projetos e interessados em se aprimorar e progredir funcionalmente, o que dá uma condição diferenciada de sujeitos no momento das projeções das escolhas no instrumento de investigação. 
Na continuidade das considerações dos perfis dos professores, outro aspecto é a idade em que se encontram. Segundo o questionário de perfil, a maior incidência $(32,5 \%)$ é de professores entre 30 e 39 anos e entre 40 e 49 anos (31,2\%) diferença pouco significativa entre as duas faixas etárias.

Uma pesquisa de Leme (2006) mostrou que professores/gestores mais jovens em idade podem ser mais democráticos, valorizar mais o estabelecimento de regras por todos, considerar como gravidade máxima as infrações e agressões entre alunos e dar grande importância à estabilidade do corpo docente, aos problemas de aprendizagem dos alunos e à autonomia da equipe gestora. Deluty (1979), em suas pesquisas com a Children's Action Tendency Scale, também constatou que vários fatores variam de acordo com a idade dos sujeitos pesquisados e que deve ser um aspecto considerável nas conclusões.

Os professores mais jovens também se preocupam mais com os problemas de convívio na escola, conflitos entre alunos, vandalismo contra o patrimônio escolar e ausência de controle dos professores sobre suas classes. Leme (2006) constatou ainda que os gestores mais jovens são menos punitivos, aplicam menos sanções, como expulsões, denúncias e transgressões.

Como um dos valores estudados nesta pesquisa é a convivência democrática, a importância da idade foi verificada como uma variável interessante, "especialmente na valorização de opiniões e aspectos ligados ao favorecimento do funcionamento e convívio" (LEME, 2006, p. 67). Mais uma hipótese a ser considerada para a forte adesão aos valores e grande incidência de escolhas para P3, nos resultados de aplicação do instrumento.

\section{ANÁLISES DOS ITENS COM TEMÁTICA ESCOLAR}

O horizonte de estruturas, valores, atitudes e práticas que se espera transformar ou construir nas escolas contempla diferentes escalas, como: diversificar a demanda, incluir os valores da democracia, incluir conteúdos sociomorais, mudar as formas de organização e os métodos de trabalho, procurar uma educação com sentido ético mediante a aprendizagem 
vivencial e, fundamentalmente, formar docentes comprometidos com a promoção e a vivência dos valores democráticos. Como o professor é nosso interesse neste estudo, optamos por discutir mais especificamente os resultados e os itens relativos à temática escolar do instrumento de valores que também apresentaram resultados com altos índices para a alternativa $\mathrm{P} 3$.

As situações escolares apresentadas nos dois cadernos, no geral, são muito próximas às situações que os professores vivenciam diariamente nas escolas. Colocando-se na situação dos protagonistas ou em oposição a eles, os professores respondentes à pesquisa têm essas temáticas muito presentes em suas vidas profissionais, o que provoca uma empatia importante para responder às questões do instrumento. Os altos índices para a alternativa P3 podem sugerir uma projeção de desejabilidade naquilo que os professores pensam que deveria ser o mais adequado a fazer, contudo, não se pode apurar se é o que realmente fazem.

Encontramos em Tostain (1999) uma explicação para as situações de justiça. Esse autor diz que há uma crença no mundo justo, o que Piaget (apud PARRAT; TRYPHON, 1998) chamou de crença na justiça imanente, ou seja, uma situação de justiça está diretamente ligada aos atos cometidos e o mundo é justo no sentido de que as pessoas têm aquilo que merecem. Para amenizar essa crença, Tostain (1999) explica que, quanto mais próximo da vítima está o sujeito, mais há a possibilidade de compreendê-la. Há o que o autor chama de identificação. Para Tostain (1999), quanto mais os sujeitos encontram semelhanças, afinidades com as vítimas, mais aparece a sensação de empatia e mais valorizam a própria vítima. Por isso, situações escolares que apontam possibilidades de diminuir os efeitos na crença do mundo justo podem colocar rapidamente os professores no lugar dos protagonistas e causar a identificação com eles.

Foram selecionados alguns itens do valor justiça nos dois cadernos, que tratam justamente destas questões: discriminação, desigualdade de tratamento, autoritarismo e exclusão. Esses temas, que são grandes obstáculos e que dificultam as relações interpessoais e a boa convivência na escola, 
deveriam ser os aspectos primordiais a serem pensados nas propostas de mudança.

a) No Caderno 1, os itens 9, 15 e 20 são referentes às questões escolares:

- item 9: trata de uma situação de discriminação, de aluno que precisa de ajuda porque é muito fraco. A alternativa P3 apresentou 56\% das escolhas;

- item 15: fala do tema da desigualdade, de uma professora que age de forma diferente com os alunos de escola pública e de escola particular. A alternativa P3 teve $66 \%$ das escolhas;

- item 20: é sobre o tema do autoritarismo, de professora que muda o que estava anteriormente combinado com a classe. Foram 61\% das escolhas para P3.

b) No Caderno 2, os itens 1, 10, 12, 13 e 18 são referentes ao tema escolar:

- item 1: trata de uma situação de discriminação, de meritocracia, de uma professora que se comporta de forma diferente com os alunos em decorrência de suas notas. A alternativa P3 obteve $85 \%$ das escolhas;

- item 10: fala de uma situação de injustiça por favorecimento, de professores que recebem favores do diretor pelo grau de amizade que têm com ele. A alternativa P3 apresentou 83\% das escolhas;

- item 12: descreve uma situação de colaboração da professora a um aluno pobre que facilitaria o seu transporte para a escola, mas que esbarra nas normas escolares. A alternativa que corresponde a P3 teve $71 \%$ das escolhas;

- item 13: trata de situação de inclusão de criança com distúrbio no ambiente escolar e pressão das famílias das outras crianças. A alternativa correspondente a P3 foi de 83\% das escolhas;

- item 18: este item já foi mencionado anteriormente pelo resultado polêmico - são $98 \%$ das escolhas para a alternativa que corresponde a P3. Trata-se de uma situação de autoritarismo, de quebra de 
combinado entre a professora e os alunos, de desrespeito ao trato feito, além de mostrar posição bastante discriminadora da professora em relação ao aluno bagunceiro.

Para que possam ocorrer as transformações estruturais na escola, assinalam-se: o abandono à racionalidade instrumental, o desenho de um currículo permeado transversalmente pelos temas dos direitos humanos e da democracia, o estabelecimento de condições e procedimentos para que as instituições educacionais sejam dirigidas e supervisionadas por pessoas comprometidas com os valores educacionais (ALBA et al., 1989), e, ainda, promover a autonomia local em torno de decisões relativas à educação e propiciar a autonomia pedagógica dos estabelecimentos.

A real transformação do sistema educacional se dará a partir do conjunto de mudanças nas escolas e nas atitudes dos sujeitos escolares, principalmente os professores. É esperado que as escolas se constituam como espaços sociais formadores de cidadãos e produtores de uma cultura da democracia, ainda que alguns autores reconheçam as limitações dessa instituição como agente de mudança social frente a outros agentes socializadores e frente a outras esferas de decisão política e econômica.

Como uma primeira proposta de reflexão para a mudança, sugere-se dar um tratamento significativo aos temas da democracia e dos direitos humanos, incorporando a prática, a vivência e os saberes da vida cotidiana das crianças (ALBA et al., 1989), e envolvendo toda a instituição escolar no processo de educação para a democracia mediante o trabalho de equipe, o fortalecimento do trabalho colegiado e a elaboração de projetos institucionais.

Foram selecionados os itens do valor respeito em situações escolares do instrumento, que tratam destes aspectos: temas referentes à discriminação, inclusão/exclusão, violação dos direitos e desrespeito às diversidades de gênero e de raça.

a) No Caderno 1, os itens 2, 12 e 16 tratam de questões escolares:

- item 2: discorre sobre uma situação de desrespeito, de violação dos direitos legalmente constituídos, 
de inclusão de criança com Síndrome de Down no ambiente escolar. O índice de 79\% para P3 aparece nas escolhas;

- item 12: trata da política de inclusão atual para crianças com deficiência, no caso deficiência física. A alternativa correspondente a P3 obteve $69 \%$ das escolhas;

- item 16: descreve a temática do desrespeito à privacidade, de professora que quer discutir sobre sexualidade em sala de aula de ensino médio, invadindo a intimidade dos alunos. Foram $61 \%$ das escolhas para a alternativa P3.

b) No Caderno 2, os itens 2, 14 e 19 abordam situações escolares:

- item 2: já mencionado anteriormente - trata de uma situação de desrespeito, de exclusão e discriminação de aluna homossexual, de fofocas e comentários indevidos. Foram 91\% das escolhas para P3;

- item 14: já mencionado anteriormente - é sobre o desrespeito à lei, sobre a discriminação a um professor homossexual aprovado em concurso que está sendo impedido de assumir o cargo. Foram 51\% das escolhas para P3;

- item 19: trata de situação de cyberbullying, de discriminação e exclusão social. A alternativa correspondente a P3 obteve $76 \%$ das escolhas.

Segundo Fuentes Molinar (1994, p. 37), em propostas de educação relativas aos direitos humanos se recomenda mudar as "mais arraigadas tradições da escola, como a concepção da formação cívica", e se propõe "modificar de maneira significativa a instituição escolar” (VELAZQUEZ; RAMIREZ, 1989, p. 9).

Todas essas discussões de mudança recaem sobre a figura do professor, que pode ser considerado o protagonista da mudança. Como tal, é destinatário de uma grande quantidade de propostas de inovação e capacitação, sendo que é esperado que rapidamente incorpore habilidades especiais para realizar o seu trabalho, comprometa-se e seja coerente com os princípios e valores da democracia, da paz e dos direitos humanos. 
O professor deve mostrar coerência entre o que diz e o que faz, conhecer pessoalmente os alunos, buscar relações mais humanas com eles, evitar as formas de autoritarismo ou a ausência total de limites, aplicar novas formas de trabalho que propiciem a participação do educando nas decisões, assim como a discussão de alternativas para possíveis conflitos.

Apesar de nas últimas décadas aparecerem estudos (DEVRIES; ZAN, 1997; TOGNETTA; VINHA, 2007, entre outros) sobre cooperação, inclusão e cidadania, uma programação mais sistematizada nas escolas para o desenvolvimento do ambiente sociomoral não discriminador e não excludente ainda é incipiente, principalmente nas redes públicas. É necessário e urgente um programa escolar que favoreça a formação e a transformação do professor, no sentido de se envolver e aceitar colocar em sua prática diária os pressupostos éticos e morais, para que se possa ter uma nova geração de professores competentes moralmente e autônomos em todas as regiões do país, fortemente inclinados à adesão de valores e respeito às diferenças, e que repudiem a exclusão.

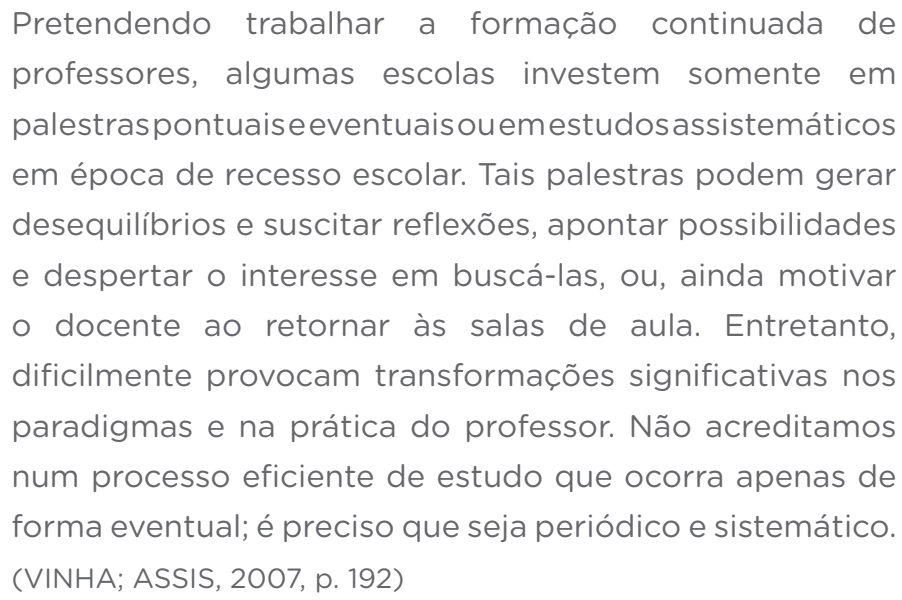

Vinha e Assis (2007) ressalta também que a aplicação desses programas na escola não é uma proposta utópica e que, a despeito das dificuldades, muitos professores já vêm adotando esses procedimentos de forma insistente e, ainda que de forma não sistematizada, os resultados positivos têm aparecido. 
A resistência dos docentes à mudança, assim como das autoridades educacionais, é atribuída à burocracia, rigidez, hierarquização do sistema, indolência e tradicionalismo; e, também, a falta de estímulos econômicos ou a má preparação dos docentes (CONDE, 1994), elementos que se colocam no caminho daquilo que se quer transformar. A intervenção de agentes externos, promotores das novas práticas e formadores dos docentes nos conteúdos e valores pertinentes, é necessária para se conseguirem as transformações. Com o grande descontentamento atual da forma como funcionam as escolas, as experiências de educação para a democracia deveriam propor alternativas e rumos para sua transformação.

Os itens selecionados da temática escolar do valor "convivência democrática" tratam dessas questões de estagnação do processo de mudança, do autoritarismo, da imposição de regras, do individualismo e da omissão, somados à violência escolar.

a) No Caderno 1, os itens 10 e 14 são com temas escolares:

- item 10: trata de uma situação de autoritarismo, de normas e regras compartilhadas ou impostas pela autoridade escolar. A alternativa correspondente a P3 obteve $69 \%$ das escolhas;

- item 14: fala da violência na escola, da discriminação, de situação que envolve o cyberbullying. A alternativa que corresponde a P3 obteve 74\% das escolhas.

b) Já no Caderno 2, os itens 17 e 20 falam do tema escolar:

- item 17: refere-se ao autoritarismo em situação de recreio escolar, com crianças que devem ficar quietas para não atrapalhar o lanche de outras. Foram $85 \%$ das escolhas para P3;

- item 20: trata de uma situação que apresenta individualismo e omissão, além do autoritarismo por parte dos gestores que oferecem favores em troca de voto em eleições escolares. A alternativa que corresponde a P3 obteve $84 \%$ das escolhas.

Pela posição que ocupam nas escolas e no desenvolvimento das experiências pedagógicas, os professores estão 
em excelentes condições de incorporarem-se ativamente na produção dos saberes clássicos e constituírem-se em atores centrais da experiência escolar, assim como têm condições de se desenvolverem como autores qualificados na construção do currículo, mas um currículo voltado para um saber pedagógico configurado e desprendido de certas ideologias que estão fortemente arraigadas à cultura escolar. Saberes centrados em ideais democráticos e solidários. Os itens selecionados do valor solidariedade tratam destas discussões: individualismo, indiferença e omissão.

a) No Caderno 1, os itens 3 e 13 tratam de temas escolares:

- item 3: é sobre uma questão de omissão, de evidência de individualismo e de indiferença, de alunos poderem participar ou não de festa de formatura. Foram $80 \%$ das escolhas para $\mathrm{P} 3$;

- item 13: trata de omissão, de evidência de individualismo, de indiferença, de uma situação de ônibus escolar que pode se atrasar por causa de uma criança. Foram 81\% das escolhas para P3.

b) No Caderno 2, os itens 16 e 21 falam de temáticas escolares:

- item 16: diz respeito à omissão e ao individualismo, que envolve a ideia de uma campanha para benfeitoria na escola, com participação ou não de professores. Foram $50 \%$ das escolhas de P3;

- item 21: trata de individualismo, de escolha em ajudar aluno com dificuldades ou ir se divertir com amigos. Foram 64\% das escolhas para P3.

A sistematização e a reconstrução democrática do saber pedagógico têm implicações no campo educacional e no trabalho pedagógico dos professores, que deve estar voltado para a indagação qualitativa, a investigação participativa e a reflexão das práticas (CONNELY; CLANDINI, 1995).

Além disso, há as implicações políticas que muitas vezes não são levadas em consideração, mas que estão diretamente ligadas à democratização da escola e envolvem práticas de participação.

Promover e sustentar condições institucionais e políticas para a produção de saberes pedagógicos por parte dos 
professores implica, fundamentalmente, mudar aspectos que estão rigidamente constituídos. Requer reposicionar os professores na rede das relações de poder e de saber, e instituir novas relações, mais horizontais e valorativas. Enfim, trata-se de gerar uma nova configuração do poder e do saber no âmbito escolar, o que não é tarefa fácil.

Contudo, não é impossível. Uma variedade de modelos para o ensino de valores éticos, com ênfase nos valores democráticos, tem se desenvolvido nos últimos anos em vários países da Europa e da América Latina com grande êxito. Esses modelos incluem alternativas para a chamada escola tradicional, nos níveis primários e secundários, assim como a formação de professores.

A preparação dos professores para a educação em valores, porém, é um dos maiores problemas que enfrentam muitos países ocidentais. Os professores não recebem nenhum tipo de educação em capacitação específica nessa área de estudo. Na maioria dos casos, a preparação de um professor é generalista. Em relação à educação moral, que não é prioridade dos sistemas educativos, acaba se constituindo como o ensino dos conceitos e definições de diferentes valores, em vez de serem oportunidades para promover o desenvolvimento moral e de valores nos alunos.

A educação para a democracia não é parte dos programas oficiais aqui no Brasil. Não há nenhuma ênfase no ensino de processos democráticos, nem na importância da participação ativa. Quando ocorre, são iniciativas muito pontuais e esporádicas, em campanhas ou projetos de curta duração, e a maior ênfase se dá somente no ensino de conceitos específicos, datas cívicas e fatos históricos. É urgente pensar em maneiras de conceber a educação de cidadãos democráticos e éticos.

A grande maioria dos problemas que enfrentamos nas diferentes sociedades do mundo está relacionada com uma falta de orientação ética e democrática por parte dos membros da sociedade, de suas organizações, instituições e governos. Por isso, a seguir, apresentamos algumas ideias para a formação de professores, envolvendo a educação em valores. 


\section{CONSIDERAÇÕES FINAIS}

Claramente, uma nova ênfase na educação em valores, com uma orientação para a educação de valores democráticos, necessita muito mais do que novos programas educacionais. A educação vive um tempo de grandes incertezas e de muitas perplexidades. A necessidade de mudança é sentida, mas nem sempre suas metas e rumos são definidos. Há excessos de discursos, redundantes e repetitivos, que se traduzem no insucesso metodológico da prática diária. Os professores precisam ser preparados para programar e desenvolver efetivamente esse tipo de educação, e as diferentes autoridades educacionais têm de assumir um compromisso mais firme para melhoria desse tipo de educação.

O campo da formação de professores está particularmente exposto a esse efeito discursivo. É difícil não se deixar contaminar por esse discurso nebuloso que ocupa todo o espaço escolar e que dificulta a emergência de modos alternativos de pensar e agir (NÓVOA; DEJONG-LAMBERT, 2003).

Segundo Nóvoa (1998), toda retórica sobre os professores implica dar-lhes uma maior visibilidade social, o que reforça o seu prestígio, mas, por outro lado, provoca os controles estatais, conduzindo, assim, a uma desvalorização das suas competências. Mas é possível, talvez, esboçar alguns pontos, sugerindo disposições que possam caracterizar o trabalho docente na contemporaneidade.

Uma primeira questão se refere ao conhecimento. $\mathrm{O}$ trabalho do professor consiste na construção de práticas docentes que conduzam os alunos à aprendizagem. "Para ser professor, não basta dominar um determinado conhecimento, é preciso compreendê-lo em todas as suas dimensões" (SHULMAN, 1986, p. 8). O trabalho docente se refere à busca de um conhecimento pertinente, que não é uma mera aplicação prática de uma teoria qualquer, mas que exige sempre um esforço de reelaboração.

A profissão é a temática seguinte. Ser professor é compreender os sentidos da instituição escolar, integrar-se numa profissão, aprender com os outros, no diálogo e na reflexão. Isso porque as escolas se constroem histórica e socialmente a partir do cruzamento de múltiplos elementos: a leitura local 
da política educacional, a cultura do entorno, a história da escola, as interações dos sujeitos, seus interesses, trajetórias e saberes, as práticas instituídas e a relação da escola com outras instâncias da sociedade.

Pode-se pensar em educar para a democracia nas escolas porque se assume que elas têm função social e causam certo impacto na configuração das relações sociais. Não se pode negar que as escolas são espaços para a formação cidadã, que provocam a reflexão da educação para a democracia - como falado anteriormente - no âmbito das práticas cotidianas, na sua singularidade e nas suas características, que permitem vislumbrar os espaços e práticas cotidianas escolares para desencadear processos de formação cidadã.

Poderia apontar a sensibilidade pedagógica como um terceiro ponto a considerar. As dimensões profissionais vão sempre se chocar com as dimensões pessoais e esse aspecto refere-se às capacidades subjetivas que se desenvolvem (ou não) no ato de educar. Tratamos aqui de uma questão relevante ao tema desta pesquisa: a concepção de valores morais e sociais que é construída na interação com o meio, ao longo do desenvolvimento. A formação de professores deve dedicar uma atenção especial às dimensões pessoais da profissão docente, trabalhando essa capacidade de relação e de comunicação que define o senso pedagógico.

É importante que os professores se preparem para um trabalho autorreflexivo, de autoconceito e de autoanálise. É preciso compreender melhor o ensino como profissão da condição humana e da condição relacional. O confronto diário a que os professores estão submetidos exige deles a superação de uma visão romântica da docência, mas trata-se de reconhecer que a necessária cientificidade do trabalho não se esgota no profissional. Segundo Nóvoa (1998), esse processo acaba sendo uma teoria da personalidade no interior de uma teoria da profissionalidade. Assim sendo, é importante estimular, junto aos futuros professores e aos iniciantes, práticas de autoformação, momentos que permitam a construção de narrativas sobre as suas próprias histórias de vida pessoal e profissional.

Nóvoa (1998) refere-se à necessidade de elaborar um conhecimento pessoal (autoconhecimento) no interior do 
conhecimento profissional e de captar o sentido de uma profissão que não cabe apenas numa matriz técnica ou científica. É essencial que cada professor adquira uma maior consciência do seu trabalho e da sua identidade como professor.

E, por fim, o quinto ponto, que destacamos como compromisso social, é o que buscamos nos resultados da aplicação do questionário de valores, pois converge para o sentido dos princípios éticos, da inclusão social e da diversidade. Intervir no espaço público da educação faz parte do ethos profissional docente.

A formação de professores deve estar marcada por um princípio de responsabilidade social, favorecendo a comunicação pública e a participação. As escolas são lugares de relação e de comunicação. A contemporaneidade exige que tenhamos a capacidade de recolocar a escola no seu devido lugar, valorizando aquilo que é especificamente escolar. A concretização dessa mudança exige uma grande capacidade de comunicação dos professores e um reforço da sua presença pública.

Nas sociedades contemporâneas, o prestígio de uma profissão mede-se em grande parte pela sua visibilidade social. No caso dos professores, estamos diante de uma questão decisiva, pois a sobrevivência da profissão depende da qualidade do trabalho interno nas escolas, mas também de sua capacidade de intervenção no espaço público da educação.

\section{REFERÊNCIAS}

ALBA, Olvera et al. Educación para la paz y los derechos humanos en la primaria. Informe de una experiencia con maestros y alumnos en Aguascalientes. Aguascalientes, México: Associación Mexicana para las Naciones Unidas, 1989.

ALVARADO, Sara; OSPINA, Héctor. La escuela como escenario potencial para la construcción de la paz: los niños y niñas como sujetos éticos. In: Ética ciudadana y derechos humanos. Una contribución a la paz. Santa Fé de Bogotá: CINDE, 1998.

BARBIER, Jean-Marie. Voies nouvelles de la professionnalisation. In: SYMPOSIUM DU RÉSEAU DE RECHERCHES ET FORMATION (REF), sept. 1998, Toulouse.

BOLÍVAR, Antonio. La identidad profesional del profesorado de secundaria: crisis y reconstrucción. Málaga: Aljibe, 2006. 
CAETANO, Ana Paula. Processos participativos e investigativos na mudança dos professores e da escola. Lisboa: Ministério da Educação, 2003.

CONDE, Silvia. Los derechos humanos en el aula. Colima: Comisión Estatal de Derechos Humanos, 1994.

CONNELY, Michael; CLANDINI, Jean. Relatos de experiencia e investigación narrativa. In: LARROSA, J. et al. Déjame que te cuente. Ensayos sobre narrativa y educación. Barcelona: Laertes, 1995.

DAY, Christopher. A reforma da escola: profissionalismo e identidade dos professores. In: FÓRUM DE DISCUSSÃO PROFISSIONALISMO DOCENTE EM TRANSIÇÃO: AS IDENTIDADES DOS PROFESSORES EM TEMPOS DE MUDANÇA, 1., 2005, Braga. Anais... Braga: Instituto de Educação e Psicologia, CIED, 2005a.

. Formar docentes. Cómo, cuándo y en qué condiciones aprende el profesorado. Madrid: Narcea, 2005b.

. A liderança e o impacto do desenvolvimento profissional contínuo de professores. In: MORGADO, J. C.; REIS, M. I. (Org.) Formação e desenvolvimento profissional docente. Perspectivas europeias. Braga: Universidade do Minho, 2007. (Cadernos CIED).

DELUTY, Robert H. The children's action tendency scale: a self report measure of aggressiveness, assertiveness and submissiveness in children. Journal of Consulting Psychology, n. 47, p. 1061-1071, 1979.

DEVRIES, Retha; ZAN, Betty. Uma abordagem construtivista do papel da atmosfera sociomoral na promoção do desenvolvimento das crianças. In: FOSNOT, C. T. (Org.). Construtivismo, teoria, perspectivas e prática pedagógica. Porto Alegre: Artmed, 1997. p. 123-140.

DUBAR, Claude. A socialização: construção das identidades sociais e profissionais. Porto: Porto, 1997.

ESTRELA, Maria Teresa. Relação pedagógica, disciplina e indisciplina na aula. 4. ed. Porto: Porto, 2002.

FUENTES MOLINAR, Olac. La educación básica y los derechos humanos. Cero em Conduta, Mexico, n. 9, p. 36 -37, 1994.

FULLAN, Michael. The new meaning of educational change. London: Routledge Falmer, 2001.

GATTI, Bernardete. Formação continuada de professores: a questão psicossocial. Cadernos de Pesquisa, São Paulo, n. 119, p. 191-204, jul. 2003.

GYSLING, Jacqueline. Profesores: un análisis de su identidad social. Santigo, CL: CIDE, 1992.

HARGREAVES, Andy. Os professores em tempos de mudança. O trabalho e a cultura dos professores na idade pós-moderna. Lisboa: McGrawHill, 1998.

KOHLBERG, Lawrence. The Philosophy of Moral Development. New York: Harper and Row, 1984. 
. Psicología del desarrollo moral. Bilbao, Espanha: Biblioteca de Psicologia, Editorial Desclée de Brower, 1992.

KOLLER, S. H. et al. Uma investigação sobre os instrumentos de medida de maturidade de julgamento moral em uso no Brasil. Psicologia: Reflexão e Crítica, Porto Alegre, v. 7, n. 1, p. 5-14, 1994.

LEME, Maria Isabel da Silva. Convivência, conflitos e educação nas escolas de São Paulo. São Paulo: ISME, 2006.

LIND, Georg. O significado e medida da competência moral revisitada: um modelo de duplo aspecto da competência moral. Psicologia: Reflexão e Crítica, Porto Alegre, v. 13, n. 3, p. 399-416, 2000.

MARCELO, Carlos Garcia. Formação de professores. Para uma mudança educativa. Porto: Porto Editorial, 1999.

NÓVOA, António. Professionalisation des enseignants et sciences de l'éducation. Paedagogica Historica, n. 3, p. 403-430, 1998.

NÓVOA, António; DEJONG-LAMBERT, William. Educating Europe: an analysis of EU educational policies. In: PHILLIPS, D.; ERTL, H. (Org.). Implementing European Union education and training policy - A comparative study of issues in four members state. New York: Kluwer Academic, 2003. p. 41-72.

NUÑEZ, Iván. Valoración social de la profesión docente. Santiago, CL: Universidad Metropolitana de Ciencias de la Educación, 2000.

PARRAT, Silvia; TRYPHON, Anastasia. Jean Piaget. Sobre a Pedagogia. São Paulo: Casa do Psicólogo, 1998. Textos inéditos.

PIAGET, Jean. 0 juízo moral na criança. São Paulo: Summus, 1994.

Os procedimentos de educação moral. In: MACEDO, L. de (Org.). Cinco estudos de educação moral. São Paulo: Casa do Psicólogo, 1996. p. 1-36. (Publicação original de 1932).

REST, James. DIT Manual: manual for the defining issues Test. Minneapolis: University of Minnesota, 1986.

SELMAN, Robert L. The growth of interpesonal understanding: developmental understanding. New York: Séries Editor, 1980.

SHULMAN, Lee. Knowledge growth in teaching. Educational Researcher, n. 15, p. $4-14,1986$

TARDIF, Maurice. Los saberes del docente y su desarrollo profesional. Madrid: Narcea, 2004.

TOGNETTA, Luciene Regina Paulino; VINHA, Telma Pileggi. Quando a escola é democrática: um olhar sobre a prática das regras e assembleias na escola. Campinas: Mercado de Letras, 2007.

TOSTAIN, Manuel. Psychologie, morale et culture. L'évolution de la morale de l'enfance à l'âge adulte. Saint-Martin-d'Heres, Fr.: PUG, 1999. (Vies sociales).

VAZQUEZ, Adolfo Sánchez. Ética. Rio de Janeiro: Civilização Brasileira, 1993. 
VELÁZQUEZ, Elizabeth; RAMÍREZ, Gloria. Educación básica y derechos humanos. Mexico: Academia Mexicana de Derechos Humanos, 1989.

VINHA, Telma Pileggi; ASSIS, Orly Zucatto Mantovani de. A autonomia, as virtudes e o ambiente cooperativo em sala de aula: a construção do professor. In: TOGNETTA, L. R. P. Virtudes e educação: o desafio da modernidade. Campinas: Mercado de Letras, 2007. p. 159-197.

\section{DENISE D'AUREA-TARDELI}

Doutora em Psicologia Escolar e Desenvolvimento

Humano pela Universidade de São Paulo (USP).

Professora da Universidade Metodista de São Paulo

(Umesp) e da Universidade Católica de Santos (Unisantos).

Pós-doutoranda pela Fundação Carlos Chagas

denise.tardeli@metodista.br; dtardeli@unisantos.br 